\title{
Variations in return stroke velocity and its effect on the return stroke current along lightning channel
}

\begin{abstract}
A direct lightning strike to a tall structure can impart high impact damage to electrical equipment that may be installed within and around the structure. This is due to the behaviour of the lightning return stroke current which generates a lightning electromagnetic field (LEMF) and consequently creates an induced voltage (LIV) on the electrical equipment. The lightning return stroke current along the channel is influenced by the parameters of the return stroke velocity (RSV). The return stroke velocity can be determined by measurement. Mostly, this value is considered as the average value in the range $c / 2$ to $2 c / 3$ for the first hundred metres of channel height, which should be taken into account when calculating the LEMF. Hence, the result of the evaluation of lightning return stroke current behaviour will inherently influence the evaluation of the lightning protection that is required for the electrical equipment surrounding the tall structure. However, when performing measurements, the return stroke velocity shows a changing trend value for different channel heights. In this paper, this trend will be used to evaluate the return stroke current at different heights along a channel. Thus, modelling of a lightning current along a channel was undertaken. Also, the return stroke velocity for different channel heights was calculated by considering the initial delay time. The results indicate that the lightning current along the channel has a significant effect on the changes in the return stroke velocity profile.
\end{abstract}

Keyword: Component; Lightning; Return stroke current; Return stroke velocity 